\title{
La politique de voisinage européenne
}

Martin KoOPMANN et Christian LEQUESNE (éds), Partner oder

Beitrittskandidaten ? Die Nachbarschaftspolitik der Europäischen Union auf dem Prüfstand[Partenaires ou candidats à l'adhésion ? La politique de voisinage de l'Union européenne à l'épreuve], Baden-Baden, Nomos, 2006, 226 p. (Denkart Europa, 2).

\section{Catherine Perron}

\section{OpenEdition}

\section{Journals}

Édition électronique

URL : http://journals.openedition.org/transcontinentales/1266

DOI : 10.4000/transcontinentales. 1266

ISBN : 978-2-8218-1112-6

ISSN : 1775-397X

\section{Éditeur}

Editions de la maison des sciences de l'homme

\section{Édition imprimée}

Date de publication : 31 décembre 2006

Pagination : 154-155

ISBN : 978-2-200-92170-5

ISSN : 1950-1684

Référence électronique

Catherine Perron, «La politique de voisinage européenne », Transcontinentales [En ligne], 3 | 2006, document 14, mis en ligne le 12 octobre 2011, consulté le 25 septembre 2020. URL : http:// journals.openedition.org/transcontinentales/1266; DOI : https://doi.org/10.4000/transcontinentales 1266

Ce document a été généré automatiquement le 25 septembre 2020.

Tous droits réservés 


\title{
La politique de voisinage européenne
}

\author{
Martin KoOPMANN et Christian LEQUESNE (éds), Partner oder \\ Beitrittskandidaten? Die Nachbarschaftspolitik der Europäischen Union \\ auf dem Prüfstand[Partenaires ou candidats à l'adhésion? La politique \\ de voisinage de l'Union européenne à l'épreuve], Baden-Baden, Nomos, \\ 2006, 226 p. (Denkart Europa, 2).
}

\section{Catherine Perron}

\section{RÉFÉRENCE}

Martin KoopmANn et Christian LequeSNE (éds), Partner oder Beitrittskandidaten ? Die Nachbarschaftspolitik der Europäischen Union auf dem Prüfstand [Partenaires ou candidats à l'adhésion? La politique de voisinage de l'Union européenne à l'épreuve], Baden-Baden, Nomos, 2006, 226 p. (Denkart Europa, 2).

1 Symbole fort des retrouvailles paneuropéennes, c'est à Prague en juin 2004, que s'est tenue une conférence franco-allemande - rassemblant des chercheurs aussi bien français et allemands, qu'italiens, tchèques et polonais -, organisée par le CEFRES (Centre français de recherches en sciences sociales, Prague) et la DGAP (Deutsche Gesellschaft für Auswärtige Politik, Berlin), sur la " politique européenne de voisinage » de l'Union européenne. Le moment était historique : cela faisait à peine un mois que huit États situés auparavant à l'est du rideau de fer venaient d'adhérer à l'Union.

2 Avec ce qui fut célébré comme la fin du partage de Yalta et la réunification du continent, une nouvelle ère commençait pour l'Union, tant sur le plan intérieur avec dix nouveaux membres, qu'en matière de politique étrangère. De manière symptomatique, au même moment, en mai 2004, l'Union publia son " document stratégique de la politique européenne de voisinage ». C'est précisément cette réponse d'une Union européenne élargie à vingt-cinq membres aux nouveaux défis extérieurs auxquels elle se trouve confrontée, que se propose d'analyser l'ouvrage tiré de la 
rencontre organisée par le CEFRES, ouvrage dirigé par Martin Koopmann et Christian Lequesne, et paru en 2006 dans la série Denkart Europa de la Fondation Asko-Europa.

3 L'ouvrage, qui rassemble une dizaine d'articles en allemand et en anglais, offre un tour d'horizon très complet des enjeux liés à la nouvelle position géopolitique (au-delà de la politique européenne de voisinage stricto sensu comme semble pourtant l'indiquer son titre) d'une Union européenne qui, désormais, voisine directement avec de nombreux États faibles, pauvres et potentiellement exportateurs d'instabilité. Une Europe qui se voit contrainte de définir une politique envers ses voisins qui n'ait pas pour seul instrument la perspective de l'adhésion, comme ce fut le cas jusqu'à présent.

4 Soulignant l'ampleur des ambitions de la politique européenne de voisinage (atténuer la dichotomie entre membres et non-membres, relativiser l'importance des frontières extérieures de l'Union, créer de la stabilité par la convergence de systèmes, etc.), les différentes contributions insistent surtout sur ses limites (refus de la Russie d'en être partie prenante, absence d'innovation puisqu'il s'agit finalement d'une politique qui, à l'image de la politique d'élargissement, est fondée sur l'exportation des normes et valeurs de l'Union, faiblesse des moyens alloués, formalisme des relations, aspect unilatéral du dialogue...).

5 La construction de l'ouvrage en trois parties distinguant les « perspectives de voisinage à l'Est » des « formes possibles de coopération entre l'Europe et l'espace méditerranéen » et les « champs problématiques d'une politique de voisinage à venir » [tous ces titres sont traduits de l'allemand] reflète en outre la contradiction inhérente à l'hétérogénéité des pays auxquels s'adresse la politique européenne de voisinage. De la Biélorussie au Maroc en passant par le Caucase et Israël, cette politique concerne des États dont le poids et l'importance pour l'Union européenne varient très fortement (ainsi le parti pris de consacrer un article au seul cas de l'Ukraine); elle regarde à la fois le sous-ensemble géographique des pays d'Europe de l'Est qui se situent dans la continuité territoriale de l'Union et pour lesquels à terme une adhésion n'est pas impensable, et les pays du pourtour méditerranéen dont tel n'est pas l'objectif et qui représentent des enjeux stratégiques particuliers. On peut regretter qu'aucune contribution ne s'intéresse à l'espace intermédiaire que représente le Caucase.

6 Par ailleurs, si dans la seconde partie consacrée aux formes de coopération dans l'espace méditerranéen, la politique européenne de voisinage est replacée dans un contexte géopolitique plus large, dans la première partie consacrée à l'Europe de l'Est une telle mise en perspective qui prendrait en compte l'influence des États-Unis fait défaut. Cela limite la portée de l'analyse car, comme l'écrivent les deux éditeurs de cet ouvrage, « la politique européenne de voisinage soulève aussi de manière directe la question des relations entre l'Union européenne et les États-Unis d'une part, et la Russie de l'autre » (p. 14, ma traduction). 


\section{AUTEURS}

\section{CATHERINE PERRON}

Centre d'études et de recherches internationales (CERI) 